\title{
A multi-resource system for remote teaching in Astronomy : its aims, its design, the point of view of the learners
}

\author{
By Michele GERBALDI ${ }^{1}$ AND Annie XERRI ${ }^{2}$ \\ ${ }^{1}$ Université de Paris Sud - XI \\ Institut d'Astrophysique - CNRS \\ 98 bis, Boulevard Arago, 75014 PARIS - FRANCE \\ gerbaldi @ iap.fr \\ ${ }^{2}$ Centre National d'Enseignement à Distance Institut de Vanves \\ 60, Boulevard du Lycée - 92171 VANVES CEDEX - FRANCE \\ Annie.Xerri @ cned.fr
}

\section{INTRODUCTION}

A distance teaching course in Astronomy was developed three years ago by the CNED (Centre National d'Enseignement Distance) in collaboration with professional astronomers from the University of Paris Sud XI.

We wish to present our course with :

- the conceivers and designers' point of view

- the learners' point of view.

\section{Creation of the course.}

\subsection{Centre National d'Enseignement à Distance (CNED).}

The CNED was created in 1939. It is a public administration under the supervision of the French Ministry of Education. Its first founding mission is to provide teaching and training to those who cannot take courses under usual conditions. But the CNED now operates at all the levels of the educational system from primary up to higher education, in all fields of training, initial, vocational and continuing education.

In 1995-1996, 360000 students were registered in 2500 training modules.

Among them, $80 \%$ are adults, 190000 on post baccalaureat level programmes (27 000 registered students reside outside France, in 176 countries).

\subsection{A partnership between CNED and Paris XI University.}

As no such course existed for astronomy, its creation was timely. So, as we did for meteorology in 1990, the CNED which does not deliver diplomas, offered and set up a partnership through an agreement with the University of Paris XI.

We worked with a team of Professors from that university, professional astronomers who are also well-known for working in collaboration with primary and secondary school teachers (CLEA $\dagger$ ). Together we decided, conceived and designed a remote teaching course with a multi-resource system.

\subsection{Who is the course designed for?}

This course has been developed for a large audience, non-specialist, but highly motivated.

Among journalists, Astronomy is one of the most popular sciences ; nearly every week, some "hot news" in Astronomy is offered to the public on T.V. or through the newspaper channels.

† Comité de Liaison Enseignants Astronomes: a non-profit association created in 1978 
There are about 27800 amateur astronomers (1/2000 of the total population) practising their hobby in more than 425 associations or clubs ; there exist also 100 scientific associations run by the municipalities. To augment their teaching at school, the pupils come to visit those places where they can have informal scientific - and astronomical activities under the guidance of amateur astronomers or staff members. So, astronomy is widely taught outside the schools, in clubs or associations. The amateur astronomers, the staff members, feel the need for some kind of training in astrophysics : usually they have a wide knowledge in the domain of practical observation, but they need to structure their knowledge as well as to receive some kind of training on basic astrophysical concepts.

Astronomy is present throughout the French educational system : the primary school system (ages 6 to 10), the junior high school (ages 11 to 14) and the senior high school (ages 15 to 18). Very few teachers had courses in Astronomy during their university studies. Most of the teachers in the primary schools graduated with degrees either in literature or social science; very few graduated with degrees in science. So, there is a wide need for teacher training in the domain of Astronomy. To conclude, participants in such a course are expected to have academic qualifications.

\subsection{Which scientific content?}

All the texts of this remote teaching course have been produced with the aim of providing a basic knowledge in Astronomy and Astrophysics. This course offers the opportunity to get an academic credit, "diplôme d'université", at an undergraduate level for those who want it. Astronomy is, not only one of the oldest sciences, it is also a very modern and active field of research, whose discoveries are widely presented to the public by the media. The progress of this science is intimately connected to technological advances, as well as to new developments in physics.

This course ( 150 hours) has been developed, taking into account the following aspects:

- it refers to history,

- it develops the role of observation,

- it emphasizes the importance of the physical laws, mainly the gravitational law and the radiation laws,

- it presents the phenomena which are the agents of the evolution of the stars and of the Universe itself, showing the strong interaction between observation and theory.

In some cases the historical approach is used, partly because it poses the problem in its original setting and partly because it shows the iterative nature of the scientific reasoning. As far as possible, this course is based on observation: this can be done directly, in some cases by the students themselves (phases of the Moon, sunspots...) or, it is shown on several types of documents.

We would like to insist on the fact that the documents presented in this course have not been selected for their aesthetics but only for the phenomena that they are representing. One of the main objectives of this course is to demonstrate, through astronomical examples, the reasoning methods used in science. In each chapter, the manner in which astronomical phenomena are interpreted in terms of physical laws will be developed:

- this is what constitutes the foundation of astronomical knowledge.

- this goal is not easy to achieve, due to the fact that the participants to such a course have hetereogenous backgrounds. 
This course is based on the experience gained during the past twenty years, through the activities developed by the CLEA.

\subsection{Which teaching materials are provided?}

\subsubsection{Printed texts}

3 volumes have been edited instead of only one thick one. They are divided into 14 chapters ; an index, a glossary and a bibliography are included. An appendix will contain a summary of the laws of mathematics used frequently in this course as well as the main results concerning the motion of two bodies.

The printed text contains more information than that is strictly required for the examination. The motivations and the background of the students are heterogeneous, so we have included in the text, typed in small letters, some complementary information which can be read usefully only by part of the students. For example the amateur astronomers will be interested in computational details on Bouguer law, while the physics professors will read complementary computations on spectroscopic binary stars.

A leaflet of exercises with homework experiments is provided, the exercises have detailed answers to the questions. Each exercise refers to a specific chapter. Leaflets accompanying the other media are also provided and, of course, a guide for the whole course, explaining and counselling how to learn with the different teaching materials and services offered. 41 black and white photographs are printed on separate sheets; several of them are used to do some self-correcting practical work.

\subsubsection{Slides}

A set of 60 coloured slides illustrate also the various chapters or represent the result of homework experiment; a replica of a grating is also supplied for use in a homework experiment. Students are urged to make observations by themselves : these observations are helped in several cases by slides or printed pictures.

\subsubsection{Videocassettes}

Three videocassettes are included in the package sent to each student. One is 50 minutes long and is about the solar system which is described from various points of view : comparative structure of the planets, chemical composition... This video is divided into short sequences, each of them on a different topic, so that they can be looked at separately. The two other videos are 20 minutes long each; they are on the Motion of the Earth and Eclipse and Phase phenomena. These videocassettes are also divided into short sequences, all of them having motion-picture cartoons, sometimes in $3 \mathrm{D}$ to illustrate the phenomena. Each sequence can be looked at separately and without the sound. A leaflet is given with each of these twenty minute videos and for the one about Eclipses, practical exercices are suggested using the video images.

\subsubsection{Software}

Several programmes for a PC are loaded on to a micro floppydisk to illustrate in an interactive manner, planetary motions, Doppler effect, some of the radiation laws.

\subsection{Which services are offered to the students?}

Learning alone is difficult so the various services described below have been developed in such a way that the students can test their progress.

\subsubsection{Assignments}

In order to test progression in understanding, questions are distributed through each chapter, the answers being given at the end of the chapter. Moreover, 3 long home- 
work assignments are offered. They are sent to a professional astronomer who corrects them individually and sends them back with a detailed critique of the homework, any corrections needed will be completed and sent back to the students within 3 weeks.

\subsubsection{Meeting in observatories}

Twice a year, a full day meeting in a professional observatory is offered to the participants. During each of these days, several activities are offered, not only conferences but also practical activities in some places. All the professional observatories take part.

\subsubsection{Planetarium sessions}

Two planetaria participate: one located in Paris at the Science Museum: "Palais de la Découverte" and one in Brittany (Pleumeur Bodou). Each of them offers two different shows to the participants; these shows have been specially conceived for this course. These programmes have been developed in order to make phenomena clear which are difficult to understand with drawings in 2 dimensions only.

\subsubsection{Telemaitic service (E-mail with Minitel)}

A direct link with a tutor can be obtained at any time with the French E-mail system: Minitel. To use Minitel, only a telephone line is necessary. The tutor is one of the professional astronomers who corrects the homework exercises. Three services are proposed on-line with Minitel. A series of multiple choice questions on each chapter is offered, the correct answer is given on-line as well as a score. Naked eye observations are proposed for the beginner with a special emphasis on planetary observations. These ephemerides are updated every 3 months. The main role of Minitel is to establish a direct link between the student and a tutor. What is important is that the tutor is always the same person, so through the questions the tutor can acquire an overall feeling for the difficulties of the students.

This year the Minitel link can be used in a new interactive way : there is a general file where all the questions are stored, so every participant can read all of them as well as the answers of the tutor who can also give general advice on difficulties etc... (we call it - the forum). The participants can also communicate among themselves very easily with Minitel : for example some of them asked about people in their geographical area who were learning with this remote teaching course in order to be able to communicate with them directly.

\subsection{Calendar of the course.}

Students can study at their own pace and progress at their own rate (characteristic of the distance learning population). However, a written guide as well as a calendar of the course are given for help (annex 1).

\section{Registrations and exam results.}

The course is 3 years old. 1100 students were enrolled in it and $60 \%$ of them wanted to register at the university. To enroll in this course, no specific background is required, except for those who want to be registered at the University. For the latter, it is required that they obtained their diploma at the end of their high school studies (the French baccalaurat): if not, their registration at the University can be possible if they have worked for 5 years: this is a general rule of the Ministry of Labour. Of the latter group, nearly $70 \%$ sat for the exam and of these $80 \%$, depending on the sessions, passed the exam. 


\section{Student Performance}

\begin{tabular}{|c|c|c|c|}
\hline | & $1993-1994$ & 1994-1995 & $1995-1996$ \\
\hline |Students enrolled & 644 & 265 & 209 \\
\hline $\mid \begin{array}{l}\text { Students registered } \\
\text { at the University }\end{array}$ & $\begin{array}{c}378 \\
(59 \%)\end{array}$ & $\begin{array}{c}162 \\
(61 \%)\end{array}$ & $\begin{array}{c}121 \\
(58 \%)\end{array}$ \\
\hline $\begin{array}{l}\text { Students who sat } \\
\text { for the exam }\end{array}$ & $\begin{array}{c}251 \\
\text { ( } 66 \% \text { of the above) }\end{array}$ & $\begin{array}{c}111 \\
(68 \% \text { of the above })\end{array}$ & $\begin{array}{c}84 \\
\text { (69\% of the above) }\end{array}$ \\
\hline $\mid \begin{array}{l}\text { Students who passed } \\
\text { the exam }\end{array}$ & $\begin{array}{c}208 \\
\text { (83\% of the above) }\end{array}$ & $\begin{array}{c}89 \\
\text { (80\% of the above) }\end{array}$ & $\begin{array}{c}69 \\
\text { (82\% of the above) }\end{array}$ \\
\hline
\end{tabular}

\section{The learners' point of view.}

The feedback from the participants is obtained, each year, through a dense questionnaire covering the scientific content but also their feelings about the multi-resource system available.

\subsection{Which types of information have we looked for?}

We wanted to know who our students really are (gender, age, academic qualifications, occupation, place of residence, motivation...), what are their working conditions and access to equipment; also what are their reasons for taking the course. We wanted to know as well what the students think of the course : overall assessment, assessment of each teaching aid and each service, main criticism and main assets, interest in a follow up course etc...

\subsection{How many students answered the questionnaire?}

$58 \%$ answered after the first year of the course, $47 \%$ after the second year and $34 \%$ (up to now) for the third year. We were interested to note that, as we asked for it, some of them answered even when they had to stop learning during the year. Most of them did not remain anonymous - which was a possibility offered - and many of the students wrote numerous and constructive remarks and comments.

\subsection{Who are the students?}

The table shows the great variety among the learners, in every domain: variety of occupations, location, ages.... 


\begin{tabular}{|c|c|c|c|}
\hline & 1993-1994| & 1994-1995| & $1995-1996$ \\
\hline Men & $74 \% \quad \mid$ & $73 \%$ & $83 \%$ \\
\hline Women & $26 \%$ & $27 \%$ & $17 \%$ \\
\hline Teachers & $25 \%$ & $27 \%$ & $17 \%$ \\
\hline Staff members of science centers & $6 \%$ & $9 \%$ & $7 \%$ \\
\hline Engineers & $13 \%$ & $9 \%$ & $11 \%$ \\
\hline Technicians & $12 \% \quad \mid$ & $6 \%$ & $16 \%$ \\
\hline Medical professions & $6 \%$ & $9 \%$ & $6 \%$ \\
\hline Others & $38 \% \quad \mid$ & $40 \%$ & $43 \%$ \\
\hline LOCATION & 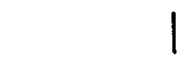 & & \\
\hline Paris and greater Paris & $24 \%$ & $23 \%$ & $27 \%$ \\
\hline Provinces & $71 \%$ & $73 \%$ & $70 \%$ \\
\hline Foreign Countries & $2 \% \quad \mid$ & $4 \%$ & $3 \%$ \\
\hline Overseas Territories & $3 \%$ & $3 \%$ & $2 \%$ \\
\hline AGES : & & & \\
\hline$>40$ years & $22 \%$ & $16 \%$ & \\
\hline$<40$ years & $53 \%$ & $61 \%$ & \\
\hline$<30$ years & $23 \%$ & $25 \%$ & \\
\hline
\end{tabular}

\subsection{What is the overall assessment of the students?}

Even with this huge variety of participants in term of:

- motivations

- ages

- professional origin

- their points of views are convergent i.e. they found the content that they expected in this course and they highlighted the pedagogical process. In fact, this purpose is met because of the large variety of resources used for this course... Nevertheless, everybody agrees that the written text is essential: it is still the corner stone of such a distance learning course. 


\subsection{What do they point out?}

Among this rich feedback, some points stand out.

4.5.1. Written text, exercises and assignments are essential for all of them.

4.5.2. To the question "What is your main criticism?" most of the answers, at the end of the first year, concerned errors in the text ("errors of youth"said some of them!), and also insufficiency in the explanations for self- correction.

4.5.3. "What do you most appreciate among the different teaching materials and services?". Each media or service is selected several times, whatever it is and students often justify their choice. These answers confirm that a large variety of resources is useful.

3.5.4. The Minitel service.

The equipment is available to $85 \%$ of the students but is used by $50 \%$ at most, depending on the rubrics offered. The non users give all kinds of reasons ("no need; no question; no reflex to use it; no Minitel available when I need one; the cost; psychological barrier...").

The users are satisfied especially by E-mail and forum and explain why they are. "clear and quick answers; reliable tutoring; availability; user friendliness; feeling of belonging to a group; making it easier to situate oneself in relation to the others; feeling of security; access to the data base of questions/answers of all...".

We must point out that despite an uptake rate of $50 \%$ at most for Minitel users, there is spin off for every student. Indeed, during the first year errata and addenda - quickly identified owing to e-mail questions from, and remarks by, students - were posted to everyone - and for the second year and subsequent sessions, teaching aids were improved thanks to the students feed back.

\section{CONCLUSION}

According to the opinions expressed by the participants, the variety of media and services used in this distance learning course fulfill their objectives because of the heterogeneity of the students, as we mentioned before, but also because of the variety of learning methods and approaches to the subject, characteristic, as we know, of each individual.

In spite of the limited use of Minitel by the students (as noted before) and the real limits of this service (difficult connexion from abroad, its cost from the French overseas territories...), we are convinced - and it was confirmed by our students - that it is a precious aid in distance teaching for tutoring as well as improving the quality of the courses.

As for the limits of the service such as it is now, they should be overcome in the near future with different networking using PCs in association with the Minitel system.

One of the major results of this distance learning course in Astronomy is that it has greatly contributed to structure the knowledge of the students, knowledge previously acquired either from long term amateur observations or from personal reading.

Following the wish expressed by numerous participants over the past three years, a second- year course based on the knowledge so far acquired is being conceived.

The following points will be included:

- scientific understanding based on the knowledge acquired in the preceding course.

- using and deepening the knowledge acquired in a perspective to interpret astronomical phenomena with the exploitation of documents, the construction of models, a critical reading of historical and contemporary texts (newspaper articles). 
M. Gerbaldi \& A. Xerri: A multi-resource system for remote teaching in Astronomy 67

We are happy to share experiences of distance teaching in Astronomy for that kind of public with you. Can we imagine a European at-distance course and certification created together? 